Published by the University of KwaZulu-Natal https://journals.ukzn.ac.za/index.php/JICBE (C) Creative Commons With Attribution (CC-BY) Journal of Inclusive cities and Built environment. Vol. 2 Issue 1

How to cite: O. Aderibigbe. 2022. Adoption of integrated transport system for sustainable transport planning and development. Conference Proceedings for International Symposium on Inclusive-Cities: Achieving Inclusive Cities Through A Multidisciplinary Approach, 2021 28-30 June. Journal of Inclusive cities and Built environment. Vol. 2 Issue 1, Pg 41-44.

\title{
ADOPTION OF INTEGRATED TRANSPORT SYSTEM FOR SUSTAINABLE TRANSPORT PLANNING AND DEVELOPMENT
}

\author{
By O. Aderibigbe
}

Published 31 January 2022

\begin{abstract}
The importance of addressing urban mobility problems is increasingly being emphasized in the Fourth Industrial Era. This shift towards creating a smart and inclusive cities represents a major milestone towards improving policies and urban mobility processes in both developed and developing cities. One approach to tackle this is the adoption of an integrated active/public transport system for urban mobility. Building on this, the study reviewed the need for integrated transport system and means to achieve a safe, efficient, accessible, and affordable transport system for all member of the society. The study revealed that good modal interchanges are central to creating a better transport network aimed at improving the transportation planning of a country. To achieve this, a well-planned and integrated transport infrastructure and services are needed and should be provided to facilitate and enhance smart mobility for all member of the society irrespective of their status or spatial location. Without planning and investment in better interchanges, the absence of affordable, efficient, and easy to use alternatives will mean those with access to a private car continue to rely on them while those without it will continue to be doubly disadvantaged by the negative social and environmental impacts of over-reliance on private cars. Thus, there is a clear and pressing need for better integration of our transport systems if our networks are to become more efficient and easier to access.
\end{abstract}

KEY WORDS Inclusive cities; Smart cities; Mobility; Transport System

Oluwayemi-Oniya Aderibigbe: Department of Urban and Regional Planning, University of Johannesburg, South Africa Corresponding Author: oboniya@uj.ac.za 


\section{INTRODUCTION}

Transport is a necessary pre-requisite that enables inclusive economic growth, poverty reduction, social progress and an overall improved quality of life. For instance, in Ethiopia, access to all roads in 15 villages has helped to reduce the incidence of poverty by $6.7 \%$ (World Bank, 2015). Investing in efficient and clean transport infrastructure and services (passenger and freight) is key to achieving sustainable economic growth, improving access to services and markets, and enhancing social wellbeing of communities, building productive capacity, as well as promoting trade and regional and global integration.

According to the World Bank (2015), adequate transport is unavailable for the world's poorest and most vulnerable people. Even though global transport investments are estimated at between US\$1-\$2 trillion per year, less than 40 percent is in developing countries; home to more than 80 percent of the world's population. Affordable transport solutions are key for the poor to access opportunities and generate savings. For example, in Nairobi, Kenya the urban poor spend up to $30 \%$ of their household income on transport (Starkey and Hine, 2014).

Transport systems have a crucial role to play in the development and growth of cities thus making human settlements inclusive; safe, resilient and sustainable. One of the targets of the sustainable development goals calls for strengthening efforts to provide access to safe, affordable, accessible and sustainable transport systems for all. It also underlines the need to pay special attention to the needs of those in vulnerable situations, women, children, persons with disabilities and older persons. Globally, the trend in traffic volume is well known, as it has been on the rise for decades. Also, mobility demand has been rising due to increased car ownership in both the developed and developing countries of the world. Andrzej (2002) asserted that the consequential effect of this is seen in traffic congestions in major cities of the world. Sustainable urban transport systems require alternatives to the use of private cars that are competitive in terms of convenience and flexibility as well as cost. Based on this, the enlargement of existing transport infrastructures may not be solution to the ever-growing traffic problems thus a need to adopt integration of transportation system.

\section{SETTINGS}

The Integrated Transportation Management Systems aims at integrating all modes and all roads into a 'system' by focusing the interest of researches, in consideration of benefits anticipated within the transport community in elevating current transportation systems to an integrated operation. In a report by the Organisation for Economic Coperation and Development OECD, (2018), to achieve a sustainable urban transport system, there is need to generate alternatives to the use of private cars that are competitive in terms of convenience and flexibility as well as cost.

One of the ways of integrating transport system is through the adoption of nonmotorized travel such as cycling to reduce over dependence and reliance on the road.

Chin and Foong (2005) defined Sustainable development as one that meets the needs of the present generation without compromising the ability of future generations to meet their own needs. Sustainable transport refers to the broad subject of transport that is sustainable in the senses of social, environmental and climate impacts. Sustainable transport aims at a proper balance between current and future environmental, social and economic qualities. Sustainable transport is a key element in development of sustainable cities. It can thus be asserted from the above that the adoption of an integrated transport system encompasses different aspect of the community and economy at large, it considers the environment by increasing the air quality and reduction in noise pollution, it also considers the inhabitants of the environment by considering their safety and satisfaction. This implies that the adoption of an integrated transport system is all inclusive of both the environment and its inhabitants.

\section{RESULT AND DISCUSSIONS}

This section discussed the measures aimed at achieving an integrated transport system in some selected countries of the world.

\subsection{GUIDING PRINCIPLES FOR THE ACHIEVEMENT OF AN INTEGRATED TRANSPORT SYSTEM;}

A report by the Chicago new transportation and mobility task force (2019), opined that for any country to be smart in terms of transport, the following principles must be adopted:

\section{A transportation system that is safe for all users:}

Safety is paramount and a core consideration of any new transportationrelated policy or program. For instance, Chicago new transportation and mobility task force in City of Chicago (2019) asserted that in 2018, Chicago had 121 fatalities. To avoid subsequent occurrence, the city sought a way to improve its streets and sidewalks, protect pedestrians, prevent crashes, and implement systems to lessen the severity of crashes

Mobility choices that are accessible, equitable, affordable, and nondiscriminatory.

Access to convenient and affordable options is not always available in every neighborhood, or to all incomes, ages, and abilities. Studies by Aderibigbe and Fadare (2018), Ipingbemi (2015) and World Bank (2015) asserted vulnerable groups such as women, aged and disabled often face transportation barriers and mobility challenges during trip making. The public transit system is the backbone of all transport modes and must be supported and complemented by new mobility options.

A city that is efficient, smart, and reliable.

The introduction and adoption of new technologies improves efficiency, access, and mobility, but the success of any country largely depends on its 
continuous usage. The use of smart technologies such as electric vehicles being used in some parts of Europe and China. Wikipedia (2021) reported that Europe had more than 3.2 million plug-in electric passenger cars and light commercial vehicles on the road at the end of 2020 .

Communities that are sustainable, healthy, and built using universal design principles.

Prioritizing health and environment as part of transportation planning is also essential achieving sustainable development.

Data and information that is actionable, transparent, shared and secured.

Information on the demographic needs of road users as well as existing transportation infrastructures are not available or not up to date. This has prevented stakeholders in making well and informed decision on the specific needs of different categories of people during transport planning (Elahi 2008).

\subsection{IMPLEMENTATION METHODS FOR THE ADOPTION OF AN INTEGRATED TRANSPORT SYSTEM;}

- Provide adequate pedestrian/ cycling walkways such as bike parking areas at stations and stops

- Integrate ticketing and information systems as well as the physical transport infrastructure.

- Integrated fares.

- Integrated service information.

\subsection{ROLES OF INTEGRATED} TRANSPORT SYSTEM IN SUSTAINABLE PLANNING AND DEVELOPMENT

- Integrate land use and transport planning:

- Improve public transport

- $\quad$ Promote safety and well-being

- Ensure social inclusion and accessibility
- Promote freight integration

- Protect the environment and overall livability of the city

- Support rural development

\section{CONCLUSION AND RECOMMENDATIONS}

The role of integrated public transport system for sustainable growth helps to promotes a safe, comfortable and livability of the community/city. Hence, regional integration should be considered so that there will be linkages between and among regions and communities. 


\section{REFERENCES}

Aderibigbe, O., and Fadare S.O. (2018). Analysis of Trip Generation Pattern of Women in the Different Residential Zones in Akure. "Futa journal of Management and Technology", 3(1\&2): 162-178.

Andrzej, A. (2002). Intelligent Integrated Transport system. 565-570

City of Chicago (2019). Chicago new transportation and mobility task force. Road map for the future of transportation and mobility in chicago. A report for the City of Chicago. Available at: https://www.chicago.gov/content/ dam/city/depts/mayor/PDFs/21755_37_ AF_MobilityReport.pdf

Chin, H.C., and Foong, K.W. (2005). Issues in transportation planning - the Singapore experience. WIT Transactions on State of the Art in Science and Engineering, 22: 127-158.

Elahi, A. (2008). Challenges of data collection in developing countries- the Pakistan experience as a way forward. Statistical Journal of the IAOS, 25(1,2), 11-17.

Ipingbemi, O. (2015). Mobility challenges and Transport safety of People with Disabilities (PWD) in Ibadan, Nigeria. African Journal for the Psychological study of Social Issues. 18: (3), 15-28.

Organisation for Economic Cooperation and Development OECD. (2018). Integrating urban public transport systems and cycling. Summary and Conclusions of the International Transport Forum (ITF) roundtable on integrated and sustainable urban transport held in Tokyo, between 24-25 April, 2017.

Starkey, P., \& Hine, J. (2014).

Poverty and sustainable transport: How transport affects poor people with policy implications for poverty reduction. A literature review. UNHabitat/ODI Report Available at: https:// sustainabledevelopment.un.org/content/ documents/1767Poverty $\% 20$ and $\% 20$ sustainable\%20transport.pdf
Wikipedia. Plug.in electric vehicles in Europe. (2021). Available at: https:// en.wikipedia.org/wiki/Plug-in_electric_ vehicles_in_Europe

World Bank. For Persons with Disabilities, Accessible Transport Provides Pathways to Opportunities. https://www.worldbank.org/en/news/ feature/2015/12/03/for-persons-withdisabilities-accessible-transportprovides-pathways-to-opportunity. (2015). 